193) has used Hess's methods on the larvæ of Calliphora erythrocephala (Blowfly), and finds that they are totally colour-blind.

Professor C. S. Sherrington has devised a simple apparatus for demonstrating the Listing-Donders Law ( $J l$. of Physiol., Vol. L, p. 46, 1916).

J. W. Nordensson (Svenska Läkaresällskapets Handlingar, Vol. XLII, p. 1126, 1916) returns to the perennial question of the form of the. lens surfaces during accommodation, and finds that during a change of 5 or $6 \mathrm{D}$. the curvatures of the two surfaces are increased at the periphery as well as at the centre. The curvature of the centre is greater than that of the periphery both at rest and during accommodation. His results thus negative Tscherning's theory and support that of Helmholtz.

Percy W. Cobb has already published two excellent papers on the effect on foveal vision of bright surroundings (P. W. Cobb and L. R. Geissler, Psychol. Rev., Vol. XX., p. 425, 1913 ; P. W. Cobb, Psychol. Rev., Vol. XXI, p. 23, 1914). He now contributes a third (Jl. of Exp. Psychol., Vol. I, p. 417, 1916).

The war has brought into prominence many problems relating to the visibility of objects under various atmospheric conditions. One such problem deals with the perception of flashes of light of brief duration. It has already attracted attention in times of peace, for upon it depends the efficiency of lighthouse flashlights and so on. McDougall's investigations on recurrent vision (Brit. Jl. of Psychol., Vol. I. p. 78, 1904) led him to the conclusion that the dimmest light visible to the peripheral retina of the dark-adapted eye, i.e., the dimmest light perceptible under the most favourable circumstances, must be allowed to act for a period of not less than one-fifth of a second in order to be perceptible. A. Blondel approaches the subject from the point of view of the physicist. He has recently discussed (Comptes Rendus, Vol. CLXII, p. 587, 1916) the perception-limit of luminous signals produced by revolving beams of low divergence, and described an apparatus allowing comparison of brief light-flashes giving the same quantity of illumination in different times. In another paper (A. Blondel and J. Rey, Comptes Rendus, Vol. CLXII, p. 861, 1916) he discusses the comparison from the point of view of carrying range of brief lightsignals produced in a revolving apparatus by light sources allowing different durations of impression upon the eye, and the conditions determining the highest effectiveness of the light-flux employed.

\title{
Colour Vision
}

The work of H. E. Ives on flicker photometry reaches a very high standard. His studies in the photometry of lights of different 
colours (Philos. Mag., Vol. XXIV, 1912) cannot be neglected by anyone interested in the subject, one of great theoretical and practical importance. He has recently published a paper (H. E. Ives and E. F. Kingsbury, Philos. Mag., Vol. XXXI, p. 290, 1916) continuing the earlier series, and dealing with the theory of the flicker photometer under unsymmetrical conditions. The same subject is dealt with from the more purely physiological point of view by C. E. Ferree and Gertrude Rand (Jl. of Exp. Psychol., Vol. I, p. 1, 1916), who describe a new method of heterochromatic photometry by the equality of brightness method, using the peripheral retina for eliminating the colour element.

Sir William Abney and W. Watson have published an important paper (Phil. Trans. R. S., Vol. CCXVI, A, p. 91, 1916) on the threshold of vision for different coloured lights.

Another case of violet or yellow-blue blindness, occurring in a healthy master of arts, aged 31 years, has been exhaustively examined by Sidney Abrutz ("Psyke" Meddelanden f. d. psykolog. Labor, Uppsala, Vol. I, pp. 2, 130, 1916). Helmbold (Arch. of Ophthal., Vol. XLV, p. 270, 1916) describes a matching test for the examination of colour vision, somewhat on the lines of Nagel's testcards.

R. A. Houston (Proc. R. S., Vol. CXII A, p. 424, 1916; Science Progress, 1917, p. 377) brings forward yet another theory of colour vision, based on the analogy of the selective action of the eye to the forced vibrations of a pendulum.

\section{Antityphoid Inoculation and Ocular Lesions}

Among the recently recorded sequelæ of antityphoid vaccination will be found a few examples of ocular lesions.* Although the number of reported cases is very limited, attention may well be drawn to them. It is important that all pathological phenomena arising in patients immediately or shortly after inoculation should be thoroughly investigated and that every endeavour should be made to determine if the relation between the vaccination and the subsequent lesions is causal or merely incidental. This question will doubtless be fully dealt with when the results of antityphoid inoculation in the Navy and Army during the last three years are published.

In a recent report to the Under-Secretary of State for Public Health in France, de Lapersonne, while recognizing the importance of the question under consideration, and the reliability of some of the observations, states that of the cases of ocular lesions following

\footnotetext{
*Morax.-Annal. d'Oculist., May and Nov., 1916.

Bond.-Canadian Med.Jl., 1915, p. 398.

de Lapersonne.-Arch.d'Ophtal.. March-April, 1917.
} 